\title{
Cardiovascular Effects of NPK-1886, a New Dihydropyridine Compound with Calcium Entry Blocking Activity
}

\author{
Jun NAGURA, Bunsei MURAYAMA, Nobuo HARADA, Kunio SUZUKI, \\ Tetsuji MIYANO, *Michio YAJIMA and *Kazumi TAKEYA \\ Central Research Laboratories, Banyu Pharmaceutical Co., Ltd., \\ 2-9-3 Shimo-Meguro, Meguro-ku, Tokyo 153, Japan \\ *Department of Pharmacology, Aichi Medical University, \\ Nagakute, Aichi 480-11, Japan
}

Accepted November 22, 1985

\begin{abstract}
The cardiovascular effect of NPK-1886 (NPK), a novel photostable dihydropyridine compound, was studied by comparing it with that of nifedipine (Nif). In normal Wistar rats (NWR), systolic blood pressure was only slightly depressed by NPK or Nif, while in three types of hypertensive rats (i.e., spontaneously hypertensive rats $(\mathrm{SHR})$, renal hypertensive rats $(\mathrm{RHR})$ and DOCA-saline-induced hypertensive rats (DOC-Na-R)), the hypotensive potency of NPK was more than or equal to that of Nif. The effectiveness of NPK on the normal and hypertensive models was in the following order: DOC-Na-R, RHR, SHR, NWR. Coronary perfusion flow in Langendorff's heart was increased almost the same extent by NPK and Nif. On isolated rabbit aortic strips, the antagonistic potencies of NPK, like those of Nif, were greater for calcium than for norepinephrine, serotonin and angiotensin II. The negative ino- and chronotropic potency of NPK in isolated guinea-pig right atria was less than that of Nif. The slow membrane action potentials of guinea-pig papillary muscle were suppressed by NPK, but less than by Nif, with manifestations of a reduction of $\dot{V}_{\max }$ and AP-duration. These results indicate that NPK has a potent hypotensive effect on hypertensive models and a weaker cardiac inhibition. The general toxicity of NPK was lower than that of Nif.
\end{abstract}

Calcium entry blockers which block the calcium channels of cell membranes have significant effects on the cardiovascular system $(1-9)$ : they share a common ability to decrease pacemaking activity, reduce cardiac muscle force development, and relax vascular smooth muscle. In the heart, the calcium entry blockers have some crucial advantage for amelioration of the state of disordering of the circulation. They increase blood flows in the coronary vessel and other systemic vascular beds, diminishing afterload on cardiac muscle during blood ejection, and dispensing the oxygen consumption of the heart $(10)$. In addition, calcium overload into the cell caused the death of the cell. Henceforth, calcium entry blockers were reported to protect the necrosis or mortal calcification of the cell $(11,12)$.
Nifedipine, a prototype calcium entry blocker was first reported by Bossert and Vater (13) and the mechanism of action was elucidated by Fleckenstein et al. (14, 15). Thereafter, many kinds of organic substances were introduced as a class of calcium entry blockers, but there was no common chemical structure essential for calcium entry blocking action (16). Because of considerable heterogeneity in the affinity of different cells for calcium entry blockers, some modification of the molecule of nifedipine yielded some different potencies on the blood vessel and heart, although the essential mechanism of action was the same (17).

An ideal calcium entry blocker should therefore have a low general toxicity and selective action on some specific part of the circulatory system and, in connection with 
<smiles>CC(=O)C1=C(C)NC(C(=O)OC(C)C)=C(C(=O)OC(C)C)C1c1cccc(Cl)c1Cl</smiles>

NPK-1886<smiles>COC(=O)C1=C(C)NC(C)=C(C(=O)OC)C1c1ccccc1[N+](=O)[O-]</smiles>

Nifedipine

Fig. 1. Chemical structures of NPK-1886 and nifedipine.

nifedipine, a photostable nature. With this aim. Miyano et al. (18) synthetized many dihydropyridine compounds, the number exceeding 300. Among them, we found NPK1886 to be a compound ideal for antihypertension at the present stage. The chemical structure of NPK-1886 is isopropyl methyl 2-carbamoyloxymethyl-6-methyl-4-(2,3dichlorophenyl) -1,4-dihydropyridine-3,5dicarboxylate (Fig. 1). In this paper, we reported on the cardiovascular effects of NPK-1886, comparing them with those of nifedipine as a prototype dihydropyridine calcium channel blocking agent.

\section{Materials and Methods}

1. Measurement of blood pressure in rats: Normal Wistar rats (NWR) and hypertensive model rats (spontaneously hypertensive rats (SHR), renal hypertensive rats $(R H R)$ and DOCA-saline-induced hypertensive rats (DOC-Na-R)) of the male sex, weighing from 250 to $350 \mathrm{~g}$, were used. The animals were warmed-up in a box maintained at $37^{\circ} \mathrm{C}$ for $15 \mathrm{~min}$ prior to the experiments. The systolic pressure in the tail arteries of rats was measured in the conscious state using plethysmographical units connected with a tail-cuff (Ueda Co. VSM-10-S). Male SHR, 13-20 weeks of age, were used. RHR were prepared by the following methods: the left renal artery of rats (Wistar strain) under ether anesthesia was isolated and loosely ligatured by a silver wire at a slit width of $0.2 \mathrm{~mm}$. Seven days after the operation, the residual right kidney was extirpated. Four weeks thereafter, the hypertensive state had developed, and the animals were then used. Rats of DOC-Na-R were prepared as follows: healthy male rats (Wistar strain) first received the left kidney extirpation at 5 weeks after birth. One week after the operation, $1 \%$ saline solution was administrated ad lib, and desoxycorticosterone acetate (DOCA) was injected hypodermally once a week in a dose of $5 \mathrm{mg} /$ animal. The blood pressure monitoring was made 4 weeks after the first DOCA injection, and the rats in a hypertensive state of over $160 \mathrm{mmHg}$ were used in the experiment.

2. Experiments on vascular system: To measure coronary flow, the heart was rapidly isolated from albino rabbits of either sex, weighing about $1.5 \mathrm{~kg}$, and Langendorff's heart was made by cannulating into the aorta. Well oxygenated Krebs-Henseleit solution (compositions in $\mathrm{mM}: \mathrm{NaCl}, 115 ; \mathrm{KCl}, 4.7$; $\mathrm{CaCl}_{2}, 3.2 ; \mathrm{MgCl}_{2}, 1.2 ; \mathrm{KH}_{2} \mathrm{PO}_{4}, 1.2$; $\mathrm{NaHCO}_{3}, 24.9$; and glucose, 10.0 ) at $30 \pm 1{ }^{\circ} \mathrm{C}$ was perfused into the vascular bed of the heart. The negative logarithms of the concentration of test substances showing a 50\% increase in perfusion rate was used as an index of the vasodilating potency.

Spirally cut strips (width $2 \mathrm{~mm}$, length 20 $\mathrm{mm}$ ) of blood vessel were made from the thoracic aorta of rabbits stunned by a blow on the head and exsanguinated, and the strips were suspended in a bath $\left(37^{\circ} \mathrm{C}\right)$ at a resting tension of $1.5 \mathrm{~g}$. The strips were first incubated for $1 \mathrm{hr}$ in normal Tyrode solution (compositions in $\mathrm{mM}$ : $\mathrm{NaCl}, 137 ; \mathrm{KCl}, 2.7$; 
$\mathrm{CaCl}_{2}$, 1.8; $\mathrm{MgCl}_{2}$, 1.1: $\mathrm{NaH}_{2} \mathrm{PO}_{4}, 0.4$; $\mathrm{NaHCO}_{3}, 12$; and glucose, 5.6), and then the bath solution was replaced by $\mathrm{Ca}$-free Tyrode solution and equilibrated for at least $30 \mathrm{~min}$. Then the preparations were incubated in a Ca-free, K-rich Tyrode solution. Five min thereafter, $\mathrm{CaCl}_{2}$ was added cumulatively into the solution. NPK-1886 or nifedipine was added $5 \mathrm{~min}$ before the experiment. Tension development in the strip was measured by means of a mechanoelectric transducer (Nihon Kohden SB-1T) which was connected to an amplifier and the data were recorded on oscillographic paper.

In experiments to determine the concentration-response curves of norepinephrine (NE), serotonin (5-HT) and angiotensin $I I$ (AT II) in the absence and presence of NPK1886 or nifedipine, the development of tension in aortic strips was measured under the same conditions described above by adding these agents cumulatively into normal Tyrode solution in the bath.

3. Experiments on isolated cardiac muscle: Guinea pigs of either sex, weighing 250-300 g. were stunned by a sharp blow on the head and the hearts were rapidly excised. The right atria with pacemaker activity was isolated from the heart bathed in a well-oxygenated Krebs-Henseleit solution at $30^{\circ} \mathrm{C}$. The preparation at a resting tension of $0.5 \mathrm{~g}$ was suspended in a bath containing the KrebsHenseleit solution. The force of contraction was measured isometrically by means of a force-displacement transducer (Nihon Kohden, SB-1TH) and displayed on oscillographic paper after $1 \mathrm{hr}$ equilibration in the bath. Heart rate was counted from the contraction frequency. of the right atrial preparations.

Papillary muscles were isolated from the right ventricle of the excised heart and then fixed vertically or horizontally (in case of electrical activity measurements) in a bath containing normal Krebs-Henseleit solution of $30^{\circ} \mathrm{C}$. The papillary muscles were stimulated by a rectangular pulse of $0.5 \mathrm{msec}$ duration, at a strength of 1.3 -fold threshold. The resting force was kept constant at $0.4 \mathrm{~g}$. In normal cases, stimulation frequency was $1.0 \mathrm{~Hz}$. In the case of partially depolarized papillary muscles, stimulation frequency was $0.1 \mathrm{~Hz}$ because of the severity of fully effective stimulation at a higher rate. The partially depolarized papillary muscle was made by increasing potassium concentration in KrebsHenseleit solution up to $30 \mathrm{mM}$. Slow membrane action potentials elicited from the partially depolarized cells were recorded by conventional methods using the $3 \mathrm{M} \mathrm{KCl}$ filled glass microelectrodes with a tip resistance of about 15 megohms. The parameters of slow action potential were analyzed with regard to the rate of rise $\left(\dot{\mathrm{V}}_{\max }\right)$, amplitude (Amp) and duration (APD) (19, 20).

4. Acute toxicity: Lethal dose of NPK-1886 and nifedipine was determined by the Litchfield-Wilcoxon method from the data of experiments using healthy mice and rats. Mice (male and female) weighing $20 \pm 2 \mathrm{~g}$ and male rats weighing from 150 to $220 \mathrm{~g}$ were used. These two kinds of animals were fed on solid food (Crea, CA-1) and water ad lib. The animal room temperature and humidity were controlled at $22 \pm 2{ }^{\circ} \mathrm{C}$ and $55 \pm 5 \%$, respectively. No food except water was administered $24 \mathrm{hr}$ before starting the experiments for oral administration of drugs.

5. Drug preparations: NPK-1886 and nifedipine were dissolved in polyethylene glycol 400 (PEG 400, Wako Pure Chem. Co.) and used in experiments evaluating the effects on blood pressure and the LD50 in the i.v. route. In the cases of LD50 estimation by administering the drugs in test animals in both i.p. and p.o. routes, NPK -1886 and nifedipine were suspended in $0.5 \%$ carboxymethyl celluiose (CMC) since they were not sufficiently soluble in PEG 400. In the in vitro studies, NPK-1886 and nifedipine were dissolved in dimethyl sulfoxide and then used. Experiments using nifedipine in vitro were performed in a dark room.

6. Statistical analysis: The values presented in the Figs. and Tables are expressed as the mean \pm S.E. For comparing two groups of results, statistical analyses were performed by Student's $t$-test or the paired Student's $t$-test.

7. Chemicals: The following drugs were used: nifedipine (Bayer), deoxycorticosterone acetate (DOCA, Wako Pure Chem. Co.), angiotensin II (Nakarai, Japan), norepinephrine (Daiichi Pharma. Co.). serotonin 
creatinine sulfate (Nakarai, Japan), dimethyl sulfoxide (DMSO, Wako Pure Chem. Co.). NPK-1886 was synthetized as described in a previous report (18), and its purity was ascertained by elemental analysis, IR, UV. MS and NMR. NPK-1886 is a highly photostable substance. All the other chemicals used in these experiments were of special grade and provided from commercial sources.

\section{Results}

1. Effects on blood pressure: The time courses of the effect of NPK-1886 and nifedipine on the systolic blood pressure are shown in Fig. 2. In NWR, NPK-1886 in doses of $3-30 \mathrm{mg} / \mathrm{kg}$, p.o., produced a mild lowering of blood pressure. The depressor effect of NPK-1886 was much the same as that of nifedipine.

In contrast, NPK-1886 produced a significant decrease in the blood pressure of SHR. Oral administration of NPK-1886 in doses of $3,10,30 \mathrm{mg} / \mathrm{kg}$ produced a significant decrease in systolic blood pressure dose-dependently. The maximum decrease was observed 1-3 hr after administration. Comparing the hypotensive potency of NPK1886 and nifedipine, their dose-response curves at the maximum response during the observation (for $24 \mathrm{hr}$ ) were analyzed by the least squares method, and the dose of $30 \%$ decrease in blood pressure from the control level (ED30) were used as a measure of their potency. NPK-1886 was 1.4 times stronger than nifedipine; the ED30 values of NPK-1886 and nifedipine were $10.2 \mathrm{mg} / \mathrm{kg}$ and $14.3 \mathrm{mg} / \mathrm{kg}$, respectively.

The influence of NPK-1886 and nifedipine on the systolic pressure of RHR was examined. Both drugs had a significant hypotensive effect in this model. Comparing the ED30 values, NPK-1886 was approximately two-times stronger than nifedipine because the doses in $\mathrm{mg} / \mathrm{kg}$ of these substances were 2.8 and 5.4 , respectively.

NPK-1886 and nifedipine significantly decreased the systolic blood pressure in DOC-Na-R of Wistar strain as well. The ED30 values of NPK-1886 and nifedipine in $\mathrm{mg} / \mathrm{kg}$ were 0.7 and 0.8 , respectively.

2. Effects on blood vessel: The effects of NPK-1886 and nifedipine on vascular perfusion through the heart were examined on Langendorff's rabbit heart. Test substances were injected into the cannula which was inserted to the aorta. The potency (as $\mathrm{pD}_{2}$ value) of NPK-1886 and nifedipine for increasing the flow rate by $50 \%$ was 7.09 $\pm 0.06 \quad(n=5)$ and $7.06 \pm 0.05 \quad(n=20)$. respectively.

Concentration-response curves of aortic strips in a partially depolarized state by raising external $\mathrm{K}^{+}$concentration to $40 \mathrm{mM}$ are depicted for calcium concentration in the absence and presence of NPK-1886 and nifedipine. Both substances shifted the control curve to the right in a parallel fashion. The shift powers of NPK-1886 and nifedipine. evaluated from the $\mathrm{pA}_{2}$ value, were $9.64 \pm 0.06$ $(n=6)$ and $8.80 \pm 0.17 \quad(n=5) \quad($ Fig. 3) respectively.

The antagonistic potencies of test substances for the other vasoactive agents, such as norepinephrine (NE), serotonin $(5-\mathrm{HT})$ and angiotensin II (AT II), were examined as shown in Table 1. The maximum responses of vasoactive agents were taken as $100 \%$. There were no appreciable differences in antagonistic potencies between NPK-1886 and nifedipine. The dose-response curve of NE shifted in a parallel fashion to the right in the presence of both substances like what was observed in the case of calcium ions. Both nifedipine and NPK-1886 depressed the contractile responses of aortic strips to $5-\mathrm{HT}$ and AT $\mathrm{II}$ in a non-competitive manner (Fig. 4).

3. Effects on cardiac muscle preparations: Using the spontaneously beating atrial strips isolated from the guinea-pig heart, the chrono- and inotropic effects of NPK-1886 were examined, and the results were compared with those of nifedipine. Both NPK1886 and nifedipine had negative ino- and chronotropic effects. Nifedipine was much more. potent than NPK-1886 in both effects; NPK -1886 first caused $20 \%$ negative inotropy at a concentration level of $10^{-5} \mathrm{M}$, while nifedipine caused a similar effect at $10^{-7} \mathrm{M}$ (Fig. 5, upper).

The potencies of the negative inotropic effect were also examined in the ventricular myocardium of guinea-pig papillary muscle drived at a frequency of $1 \mathrm{~Hz}$. The negative 
NPK-1886
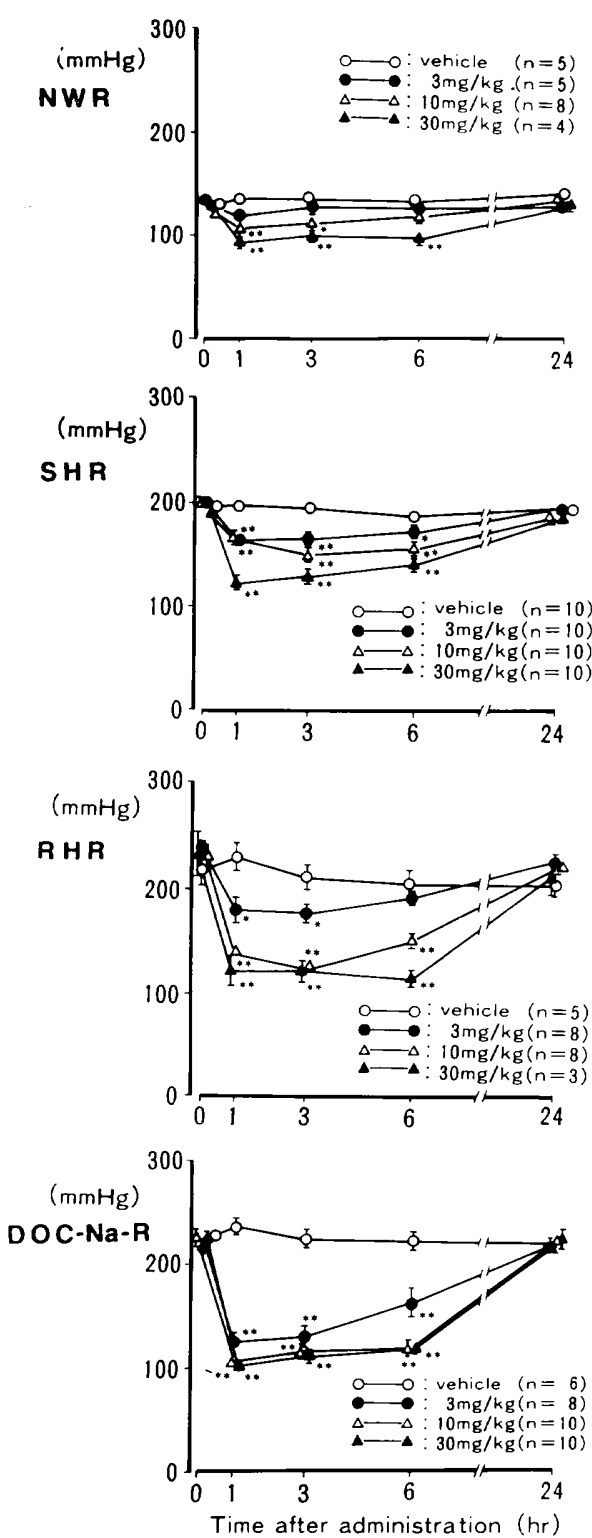

Nifedipine
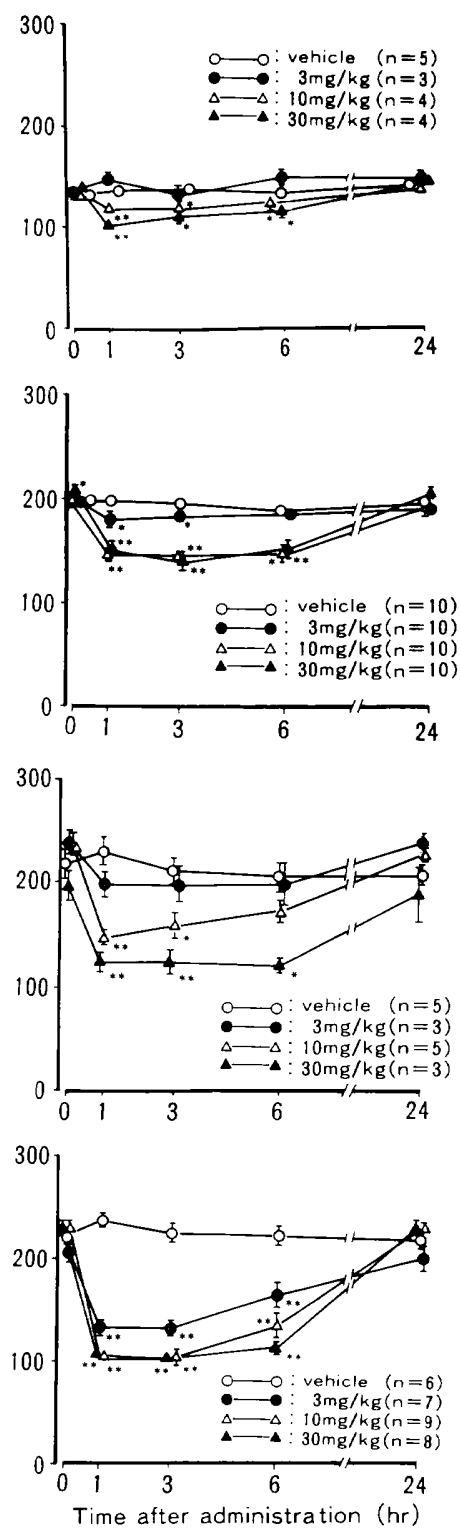

Fig. 2. Time courses of the effects of NPK-1886 and nifedipine on systolic blood pressure after their oral administration in normotensive Wistar rats (NWR). spontaneously hypertensive rats (SHR), renal hypertensive rats (RHR) and DOCA-saline-iriduced hypertensive rats (DOC-Na-R). * * **: Significant difference from the control at $P<0.05$ and $P<0.01$, respectively.

logarithms of the concentrations of NPK-1886 and nifedipine producing a 20\% inhibition ( $p / C 20)$ on the force of contraction were 6.08 and 5.97 , respectively. Hence the potency of NPK-1886 was $1 / 8$ that of nifedipine (Fig. 6).
With regard to the negative chronotropic effect, nifedipine was more potent than NPK1886 (Fig. 5, bottom); the inhibition on the heart rate was first observed at $3 \times 10^{-6} \mathrm{M}$ NPK-1886, which decreased the rate by $4.1 \%$. 

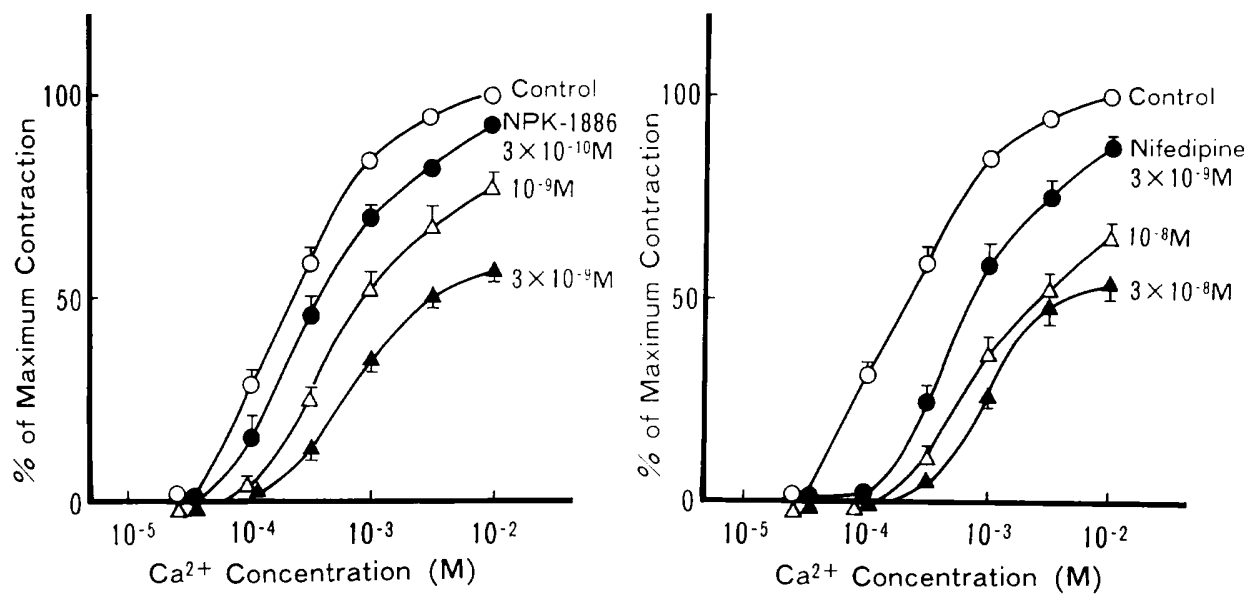

Fig. 3. Influence of NPK-1886 and nifedipine on the concentration-response curves for calcium in isolated rabbit aortic strips. Each point represents the mean \pm S.E. of 5 to 6 experiments.

Table 1. Comparisons of inhibitory potencies of NPK-1886 and nifedipine on the contractile responce of aortic strips to vasoactive agents

\begin{tabular}{llccc}
\hline Drugs & $N$ & $\begin{array}{c}\text { Norepinephrine } \\
\mathrm{pA}_{2}\end{array}$ & $\begin{array}{c}\text { Contractile agents } \\
\text { Serotonin } \\
\mathrm{PD}_{2}^{\prime}\end{array}$ & $\begin{array}{c}\text { Angiotensin II } \\
\mathrm{pD}_{2}^{\prime}\end{array}$ \\
\hline NPK-1886 & 5 & $5.00 \pm 0.14$ & $5.62 \pm 0.03$ & $4.72 \pm 0.08$ \\
Nifedipine & 5 & $5.22 \pm 0.11$ & $5.55 \pm 0.06$ & $4.64 \pm 0.05$ \\
\hline
\end{tabular}

Normal Tyrode solution, $37^{\circ} \mathrm{C}$.

while the rate decrease in the case of nifedipine at $3 \times 10^{-7} \mathrm{M}$ was $6.7 \%$. Negative chronotropic potency of NPK-1886 was approximately $1 / 10$ that of nifedipine.

Experiments were conducted to detect the inhibiting effects of NPK-1886 and nifedipine on the slow action potentials elicited from partially depolarized papillary muscles by increasing the external potassium concentration $(30 \mathrm{mM})$. The potencies of these two compounds inhibiting the slow response were examined by conventional microelectrode methods. NPK-1886 inhibited the slow action potentials at a concentration of $10^{-5} \mathrm{M}$; at this concentration, NPK-1886 reduced significantly (by about $40 \%$ ) the rate of rise $\left(\dot{V}_{\max }\right)$, amplitude and duration of slow action potential. In contrast, nifedipine completely inhibited the slow action potentials at $10^{-7} \mathrm{M}$ (Fig. 7).
4. Acute toxicity: The acute toxicity of NPK-1886 and nifedipine in mice arid rats was examined and the results are summarized in Table 2. In mice, the general toxicity of NPK-1886 was low as evaluated from the LD50 values; in the intravenous route of NPK-1886 administration, the toxicity was $1 / 2$ that of nifedipine. In the intraperitoneal route of administration, the toxicity of NPK1886 was $1 / 4$ that of nifedipine.

The LD50 values of both drugs orally administered to rats were more than $3000 \mathrm{mg} /$ $\mathrm{kg}$. In the intravenous route of administration, the general toxicity of NPK-1886 was less than $1 / 2$ that of nifedipine. In addition, PEG 400 , the vehicle of the drugs, did not have any toxic effect on mice or rats even when it was injected into the vein at a volume which was 4 -fold that contained in the maximum dose administration. 

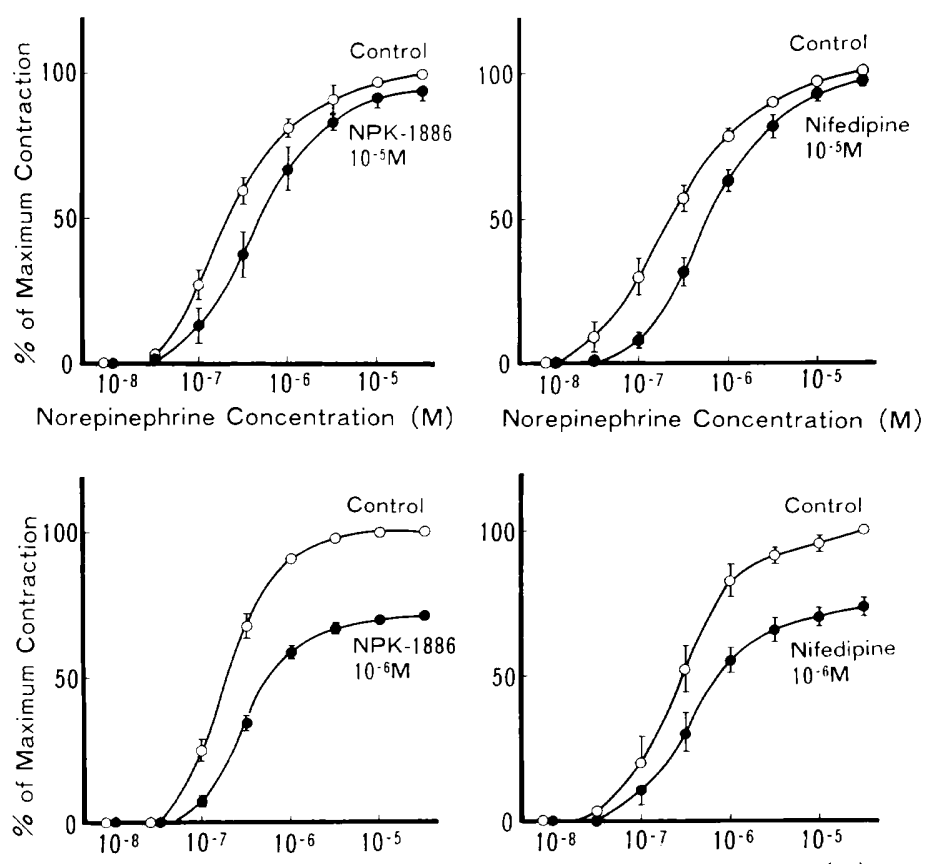

Serotonin Concentration (M)

Serotonin Concentration (M)
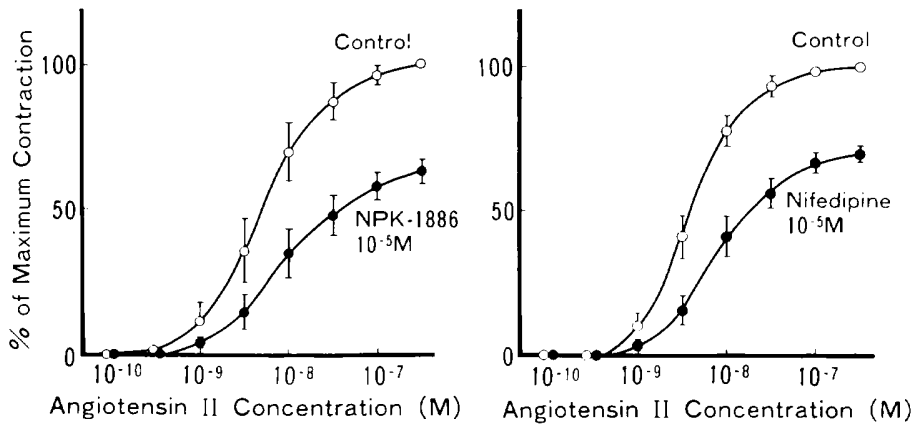

Fig. 4. Influence of NPK-1886 and nifedipine on the concentration-response curves for norepinephrine, serotonin and angiotensin 11 in aortic strips isolated from rabbits. The $\mathrm{pA}_{2}$ or $\mathrm{pD}_{2}{ }^{\prime}$ values were calculated from these curves and listed in Table 1. Each point represents the mean \pm S.E. of 5 experiments.

\section{Discussion}

The present experiments clarified that NPK-1886 has a potent hypotensive effect on hypertensive animal models such as those with spontaneously developed, kidneyoriented and DOCA-saline-induced hypertensions. The hypotensive potency of NPK1886 was estimated to be almost the same degree as that of nifedipine. Among the hypertension models used in the present experiments, DOCA-saline-induced hypertension was most effectively inhibited by both
NPK-1886 and nifedipine. Renal hypertension was also highly effectively inhibited. In contrast, the blood pressure of normotensive rats was far less effectively reduced by both $\mathrm{Ca}$-antagonistic agents. The reason why the compound was so selectively effective in hypertensive models in contrast to normotensive rats is now under discussion $(21,22)$. There is, therefore, a need to make further studies to clarify the mechanism by which these calcium channel inhibitors reduced more effectively the blood pressure of various hypertensive model rats than that of nor- 

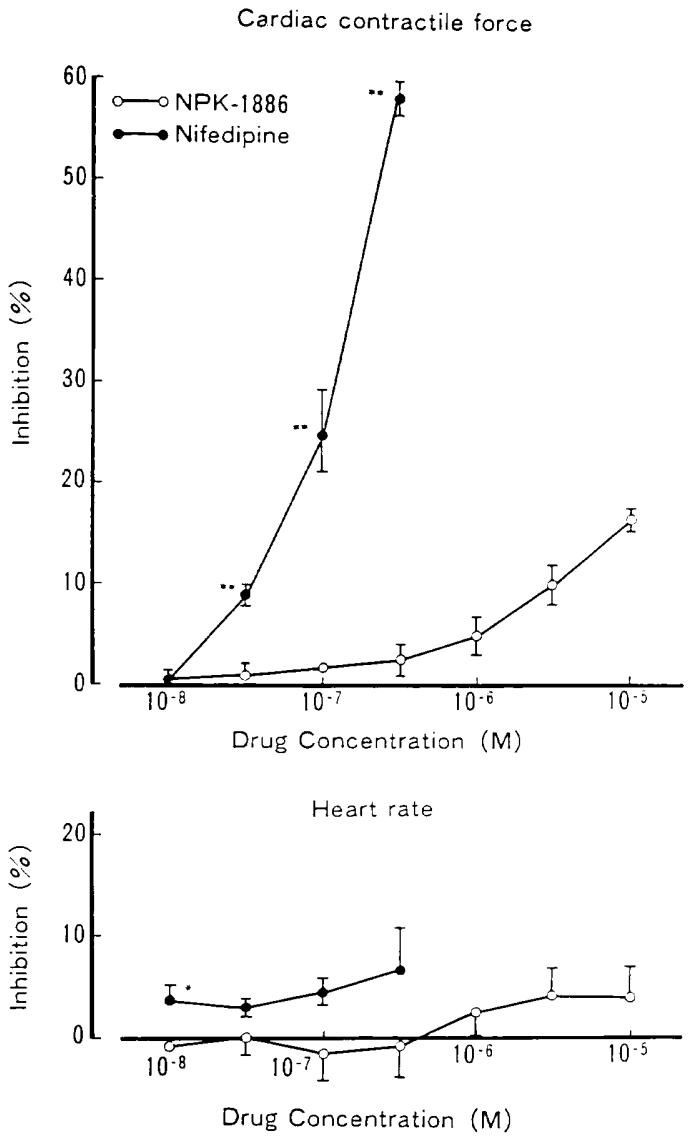

Fig. 5. Effects of NPK-1886 and nifedipine on the force of contraction and heart rate. The right atria with pacemaker activity were isolated from the guinea-pig hearts. Each point represents the mean \pm S.E. of 5 experiments. Krebs-Henseleit solution at $30^{\circ} \mathrm{C} .{ }^{*},{ }^{* *}$ : Significant difference between the effects of two drugs at $P<0.05$ and $P<0.01$. respectively.

motensive ones.

In vascular smooth muscle cells, it is known that there are two mechanisms of calcium entry: one is receptor operated $\mathrm{Ca}$ channels, and the other is voltage dependent Ca-channel (16). With regard to receptor operated $\mathrm{Ca}$-channels, it is generally known that $\mathrm{Ca}$-channel blockers such as nifedipine and verapamil are less effective for the contraction of vascular smooth muscle induced by vasoactive agents such as NE, 5-HT and AT II $(16,23,24)$. This is the case in the present experiments using NPK-1886 and

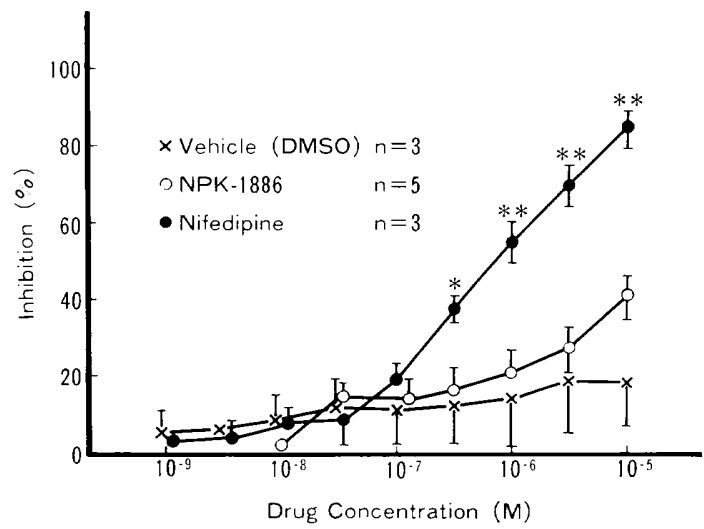

Fig. 6. Comparison of the inhibitory potency of NPK-1886 and nifedipine on the force of contraction of papillary muscles isolated from the guinea-pig heart. Krebs-Henseleit solution at $30^{\circ} \mathrm{C}$. Driving rate, $1.0 \mathrm{~Hz} .{ }^{*},{ }^{* *}$ : Significant difference from the control at $P<0.05$ and $P<0.01$, respectively.

nifedipine as well.

In contrast to the receptor-operated mechanism, NPK-1886 and nifedipine exerted their action depending upon membrane potential; they were highly effective for both cardiac and vascular smooth muscles in the partially depolarized state. The contractile response of partially depolarized vascular smooth muscle to calcium ions was clearly inhibited by NPK1886 and nifedipine. The present results can be interpreted as the indicating that NPK1886 blocked voltage-dependent calcium channels in smooth muscle cell membrane.

It has been reported that among calcium entry blockers, there are tissue differences in the potency of calcium entry blocking action. For example, nifedipine was more potent for smooth muscle relaxation than for cardiac depression; In contrast to the concentration sufficient to relax the smooth muscle $\left(3 \times 10^{-9}\right.$ $M)$, nifedipine inhibits first the heart rate, contractility and impulse conduction at relatively higher concentrations in the order of $10^{-7} \mathrm{M}$. while verapamil acts on the heart and smooth muscle functions to the same extent at a given concentration $(16,25,26)$.

In the present experiments, NPK-1886 blocked the slow action potentials of the myocardium first at relatively high concentration of $10^{-5} \mathrm{M}$, while nifedipine did that at $3 \times 10^{-8} \mathrm{M}$. In view of the results, NPK-1886 


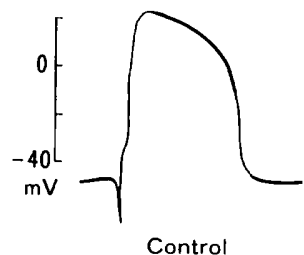

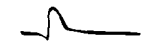

Nifedipine, $10^{-7} \mathrm{M}$

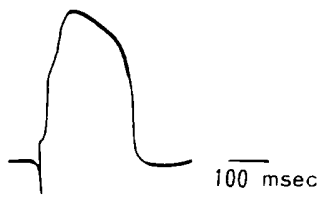

NPK-1886, $10^{-5} \mathrm{M}$
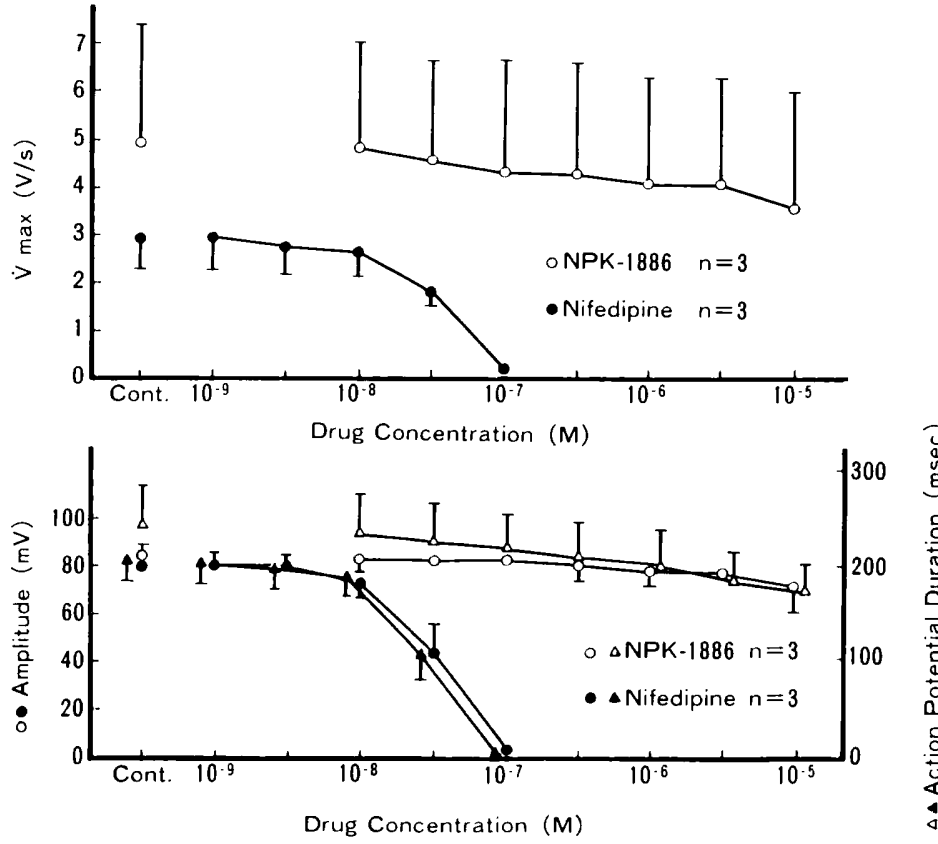

Fig. 7. Inhibitory potencles of NPK-1886 and nifedipine on the slow membrane action potentials of papillary muscle isolated from the right ventricle of guinea pig. The muscle cell membrane was depolarized by raising the external $\mathrm{KCl}$ concentration to $30 \mathrm{mM}$. The maximum rate of rise $\left(\dot{\mathrm{V}}_{\max }\right)$, amplitude and duration (at a $90 \%$ repolarization level) of slow action potential are plotted against concentration of drug. Top figures, actual recordings of slow membrane action potentials recorded from a papillary muscle.

Table 2. Acute toxicities of NPK-1886 and nifedipine in mice and rats

\begin{tabular}{|c|c|c|c|c|c|}
\hline \multirow{2}{*}{ Drugs } & \multirow{2}{*}{ Sex } & \multicolumn{4}{|c|}{ 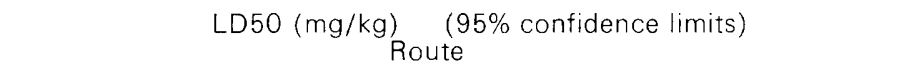 } \\
\hline & & & i.v. & i.p. & p.o. \\
\hline \multicolumn{6}{|l|}{ (MICE) } \\
\hline \multirow[t]{2}{*}{ NPK-1886 } & male & 38.0 & $(32.5-44.5)$ & $3150(2270-4380)$ & $>6000$ \\
\hline & female & 42.0 & $(36.5-48.3)$ & $3300(2540-4290)$ & $>6000$ \\
\hline \multirow[t]{2}{*}{ Nifedipine } & male & 17.0 & $(15.3-18.9)$ & $970(795-1180)$ & $420(368-479)$ \\
\hline & female & 14.5 & $(12.7-16.5)$ & $930(762-1130)$ & $310(270-357)$ \\
\hline \multicolumn{6}{|l|}{ (RATS) } \\
\hline NPK-1886 & male & 29.7 & $(26.4-33.4)$ & & $>3000$ \\
\hline Nifedipine & male & 13.0 & $(11.2-15.1)$ & & $>3000$ \\
\hline
\end{tabular}


can be estimated as being more selective for vascular smooth muscle than nifedipine is. This selectivity of NPK-1886 was also seen in the chronotropic effect (Fig. 5, bottom). The bathmotropic effect of NPK-1886 was not examined in the present study. However, NPK-1886 did not affect the electrocardiograph (ECG) of guinea pigs ( $H$. Takeshita et al., unpublished data), suggesting that there is no appreciable effect on the conduction system.

Judging from the present studies, NPK1886 is worthy of clinical trial for hypertensive disorders because of its selectivity and low general toxicity. In addition, because of the lack of a cardiac effect, NPK-1886 will improve cardiac failure by decreasing the afterload through the peripheral vasodilatatory effect.

Acknowledgement: We gratefully acknowledge the help given by $\mathrm{Mr}$. $\mathrm{H}$. Ando and other coresearchers in the Department of Pharmacology. Aichi Medical University.

\section{References}

1 Vater, W., Kroneberg, G., Hoffmeister, F., Kaller, H., Meng, K., Oberdorf, A., Puls, W., Schloßmann, K. and Stoepel, K.: Zur Pharmokologie von 4-(2' Nitrophenyl)-2,6-dimethyl-1,4-dihydropyridin3,5-dicarbonsäuredimethylester (Nifedipine. BAY a 1040). Arzneimittelforsch. 22, 1-14 (1972)

2 Grün, G. and Fleckenstein, A.: Die electromechanische Entkoppelung der glatten Gefäßmuskulatur als Grundprinzip der Cornardilatation durch 4-(2'-Nitrophenyl)-2,6-dimethyl-1.4dihydropyridin-3,5-dicarbonsaure-dimethylester (BAY a 1040, Nifedipine) Arzneimittelforsch. 22, 334-344 (1972)

3 Kosche, F., Raff, W.K. and Lochner, W.: Zum Wirkungsmechanismus der Coronardilatation durch Nifedipine. Arzneimittelforsch 22, 39-42 (1972)

4 Hashimoto, K., Taira, N., Ono, H., Chiba, S., Hashimoto, K., Jr., Endoh, M., Kokubun, M., Kokubun, H., lijima. T., Kimura, T., Kubota, K. and Oguro, K.: Nifedipine, basis of its pharmacological effect. In Proceedings, 1st International Nifedipine Adalat ${ }^{\circledR}$ Symposium, Tokyo 1973, Edited by Hashimoto, K., Kimura, E. and Kobayashi, T., p. 11-22. University of Tokyo Press, Tokyo (1975)

5 Satoh, K., Yanagisawa, T. and Taira, N.: Mechanisms underlying the cardiovascular action of a new dihydropyridine vasodilator, YC-93. Clin. Exp. Pharmacol. Physiol. 7, 249-262 (1980)

6 Ogawa, K., Wakamasu, Y., Ito, T., Suzuki, T. and Yamazaki, N.: Comparative coronary vasodilatory effects of nifedipine and niludipine. Arzneimittelforsch. 31, 770-773 (1981)

7 Satoh, K., Kawada, M., Wada, Y. and Taira, N.: Cardiovascular actions of the dihydropyridine calcium antagonist nimodipine in the dog. Arzneimittelforsch. 34, 563-568 (1984)

8 Kazda, S., Garthoff, B., Meyer, H., Schloßmann, K., Stoepel, K., Towart, R., Vater, W. and Wehninger, E.: Pharmacology of a new calcium antagonistic compound, isobutyl methyl 1,4dihydro-2,6-dimethyl-4-(2-nitrophenyl)-3,5pyridinedicarboxylate (Nisoldipine, Bay K 5552). Arzneimittelforsch. 30, 2144-2162 (1980)

9 Morita, T., Ito, K. and Nose, T.: Cardiac action of KB-944, a new calcium antagonist. Arzneimittelforsch. 32, 1053-1056 (1982)

10 Oguro, K., Kubota, K., Kimura, T. and Hashimoto, $K$.: Effects of various coronary vasodilators on myocardial oxygen consumption. Japan. J. Pharmacol. 23, 459-466 (1973)

11 Clark, R.E., Ferguson, T.B., West, P.N., Shuchleib, R.C. and Henry, P.D.: Pharmacological preservation of the ischemic heart. Ann. Thor. Surg. 24, 307-314 (1977)

12 Shen, A.C. and Jennings, R.B.: Kinetics of calcium accumulation in acute myocardial ischemic injury. Am. J. Pathol. 67, 441-452 (1972)

13 Bossert, F. and Vater, W.: Dihydropyridine, eine neue Gruppe stark wirksamer Coronartherapeutika. Naturwissenschaften 58, 578 (1971)

14 Fleckenstein, A., Tritthart, H., Döring, H.-J. and Byon, K.Y.: BAY a 1040-ein hochaktiver $\mathrm{Ca}^{++}$antagonistischer Inhibitor der elecktro-mechanischen Koppelungsprozesse im WarmblüterMyokard. Arzneimittelforsch. 22, 22-33 (1972)

15 Fleckenstein, A.: On the basic pharmacological mechanism of nifedipine and its relation to therapeutic efficacy. In Proceedings, 3rd International Adalat ${ }^{\mathbb{B}}$ Symposium, Rio de Janeiro 1975, Edited by Jatene, A.D. and Lichtlen, P.R., p. 1-13, Excerpta Medica, Amsterdam and Oxford (1976)

16 Triggle, D.J. and Swamy, V.C.: Pharmacology of agents that affect calcium agonists and antagonists. Chest 78, 174-179 (1980)

17 Triggle, D.J. and Swamy, V.C.: Calcium antagonists, some chemical-pharmacologic aspects. Circ. Res. 52 Supp. 1, 17-28 (1983)

18 Miyano, T., Suzuki, K., Harada, N., Ushizima, 
Y. and Nakagawa, S.: 2-N-Substituted or unsubstituted carbamoyloxyalkyl-1,4-dihydropyridine-3,5-dicarboxylic acid symmetrical or unsymmetrical diester derivatives and their manufacturing methods. Japan Kokai Tokkyo Koho JP 84, 152373, 531-545 (1984)

19 Nakajima, H., Hoshiyama, M., Yamashita, K. and Kiyomoto, A.: Effect of diltiazem on electrical and mechanical activity of isolated cardiac ventricular muscle of guinea pig. Japan. J. Pharmacol. 25, 383-392 (1975)

20 Hachisu, M. and Pappano, A.J.: A comparative study of the blockade of calcium-dependent action potentials by verapamil, nifedipine and nimodipine in ventricular muscle. J. Pharmacol. Exp. Ther. 225, 112-120 (1983)

21 Holloway, E.T. and Bohr, D.F.: Reactivity of vascular smooth muscle in hypertensive rats. Circ. Res. 33, 678-685 (1973)

22 Ishii, H., Itoh, K. and Nose, T.: Different anti- hypertensive effects of nifedipine in conscious experimental hypertensive and normotensive rats. Eur. J. Pharmacol. 64, 21-29 (1980)

23 Hof, R.P., Vuorela, H.J. and Neumann, P.: PY 108-068, a new, potent, and selective inhibitor of calcium-induced contraction of rabbit aortic rings. J. Cardiovasc. Pharmacol. 4, 344-351 (1982)

24 Godfraind, T. and Miller, R.C.: Specificity of action of $\mathrm{Ca}^{++}$entry blockers, a comparison of their actions in rat arteries and in human coronary arteries. Circ. Res. 52 Supp. 1, 81-91 (1983)

25 Raschack, M.: Differences in the cardiac actions of the calcium antagonists verapamil and nifedipine. Arzneimittelforsch. 26, 1330-1333 (1976)

26 Henry, P.D.: Comparative pharmacology of calcium antagonists nifedipine, verapamil and diltiazem. Am. J. Cardiol. 46, 1047-1058 (1980) 